CASE REPORT

\title{
Small cell sweat gland carcinoma of childhood
}

R Drut, O P Giménez, J Oliva

J Clin Pathol 2005;58:1328-1330. doi: 10.1136/icp.2004.024422

Small cell sweat gland carcinoma appears to represent a very unusual histological type of sweat gland anlage tumour presenting in children. The differential diagnosis from other small blue cell tumours involving the skin is often difficult. The present report confirms the original observation describing two patients of 2 and 5 years of age harbouring cutaneous tumours. The histology of these lesions showed a monomorphic proliferation of small cells with a high mitotic rate and areas of necrosis. Immunohistochemically, the cells were negative for desmin, cytokeratin 7, cytokeratin 20, Cam 5.2, CD99, chromogranin, CD56, synaptophysin, and S-100, and focally positive for the pancytokeratin marker AE1/AE3, carcinoembryonic antigen (one case), and neurone specific enolase (one case). The prognosis of this type of tumour seems to be good. As more cases are added, the clinical pathological spectrum of the lesion will become better defined.

hi 1998, Busam et al reported two children with an unusual histological type of sweat gland carcinoma, namely small cell sweat gland carcinoma. ${ }^{1}$ The authors stressed the differential diagnosis with other small blue cell tumours, either primary or metastatic, which may involve the skin at this age, in addition to the rare occurrence of this peculiar pattern in trabecular or Merkel cell carcinoma.

We report two additional cases of this unusual lesion in two children, confirming the entity and expanding the immunohistochemical findings as originally reported.

\section{CASE REPORTS}

\section{Case 1}

A 2 year old girl presented with a small $2 \mathrm{~cm}$ nodule in the skin of the anterior aspect of the thorax, clinically suspected to be a pilomatrixoma. Extensive investigation did not demonstrate metastatic disease. The patient is alive and well, without evidence of local or distant disease four years after the original diagnosis. No further treatment was given.

\section{Case 2}

A 5 year old boy underwent excision of a $6 \mathrm{~cm}$ apparently well delineated cervical subcutaneous mass. Clinical and laboratory evaluation did not reveal metastatic involvement in the regional lymph nodes or lungs. The patient did not receive further treatment.

\section{PATHOLOGICAL FINDINGS}

The histological findings of both cases were similar. The tumours were made up of large sheets and strands of poorly differentiated cells with scant cytoplasm and rounded to oval nuclei with finely stippled chromatin and dot-like nucleoli, arranged in cohesive groups. Cells having nuclei with a folded contour were also present. Mitotic figures (10-15/10 high power fields) were easily recognised, as were cells undergoing apoptosis. Clear cut glandular tubular structures were not found. Larger lobules presented areas of necrosis. The remaining cells around small vessels resulted focally in a pseudopapillary pattern. In the tumour of patient 2 there were perivascular pools of hyaline, protein rich material, and areas of loose connective tissue containing small capillaries and siderophages. The cells of the tumour of patient 1 infiltrated a densely collagenised fibrovascular stroma. Focally, these cells were spatially related to a sweat gland (figs $1-3$ ). The tumour of patient 2 seemed to be quite well delineated at the periphery by a thin delicate capsule of connective tissue containing fibroblasts and vessels. Normal tissue could not be found.

Immunohistochemistry was negative for desmin, vimentin, CD99, chromogranin, CD56, synaptophysin, cytokeratin 7, cytokeratin 20, Cam 5.2, and S-100. A consistent number of cells (approximately 30\%) from both tumours were positive for the pancytokeratin marker AEl/AE3 (fig 4A,B). Carcinoembryonic antigen was positive in a few cells of the tumour from patient 2 (fig 5), whereas neurone specific enolase was positive in the cytoplasm of groups of cells in case 1 .

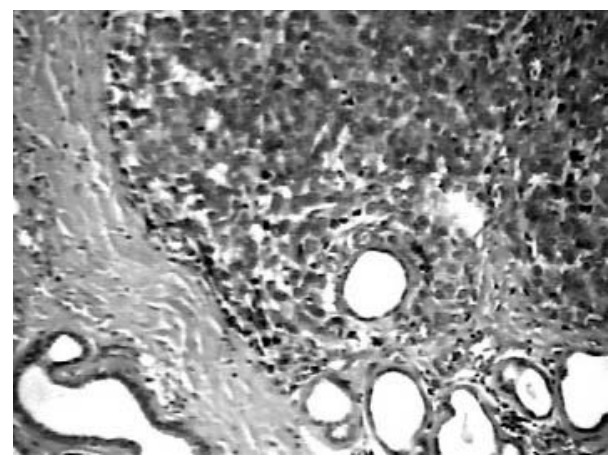

Figure 1 Medium power view of the tumour in patient 1 showing the close topographical association between the small cell proliferation and a sweat gland.

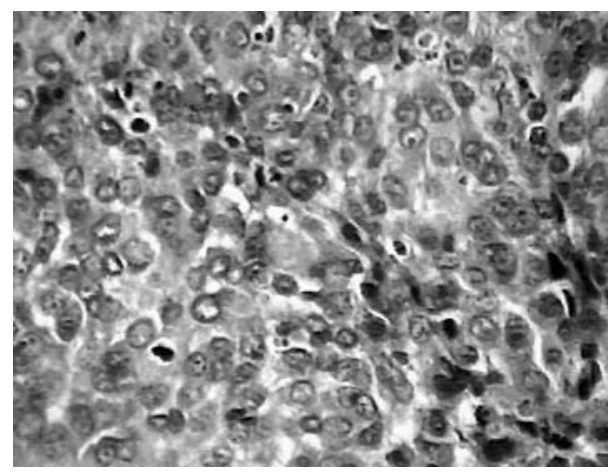

Figure 2 Cytological details of the tumour from patient 1 . 


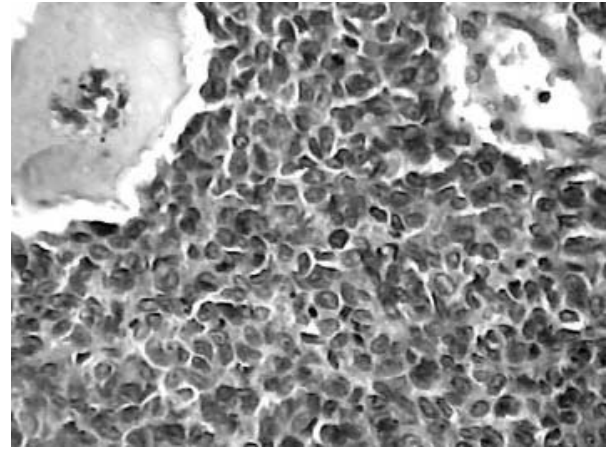

Figure 3 The cells of the tumour from patient 2 were arranged in large sheets and some local vessels contained perivascular hyaline material.

\section{DISCUSSION}

Both patients were referred as consultation cases because the original pathologist considered their case to be an example of small, round blue cell tumour, most probably requiring immunohistochemistry for a differential diagnosis. The accurate diagnosis of small cell carcinoma of sweat gland in childhood requires an awareness of the dermal-hypodermal position of the tumour and the negative immunohistochemical characteristics of the well known small blue cell tumours at this age (rhabdomyosarcoma, primitive neuroectodermal tumour, neuroblastoma, and leukaemia/lymphoma), or other small blue cell tumours that can rarely involve the skin of a child or teenager (trabecular carcinoma/Merkel cell carcinoma ${ }^{2-4}$ ). Other carcinomas of the sweat gland anlage present a spectrum of histological and immunohistochemical features that are disparate from the present entity. ${ }^{56}$

Notably, in our cases we found no "occasional tubular structures" as reported by the original authors ${ }^{1}$ in one of their patients. S-100 focal positivity was also not found. ${ }^{1}$ Swanson et al, ${ }^{7}$ studying a series of 32 eccrine sweat gland carcinomas, found that all of them expressed carcinoembryonic antigen

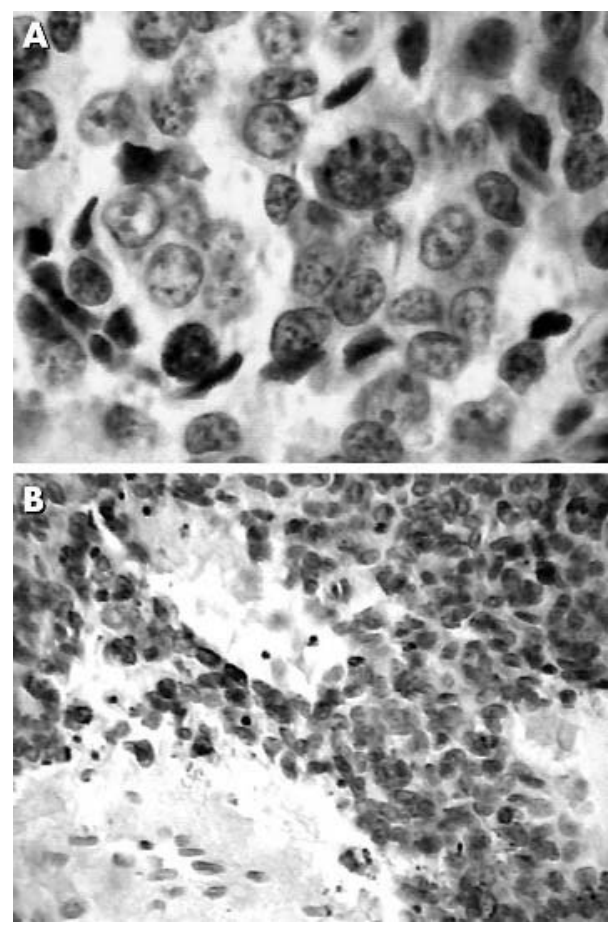

Figure 4 A small number of cells positive for the pancytokeratin marker AE1/AE3 were found in (A) case 1 and (B) case 2.

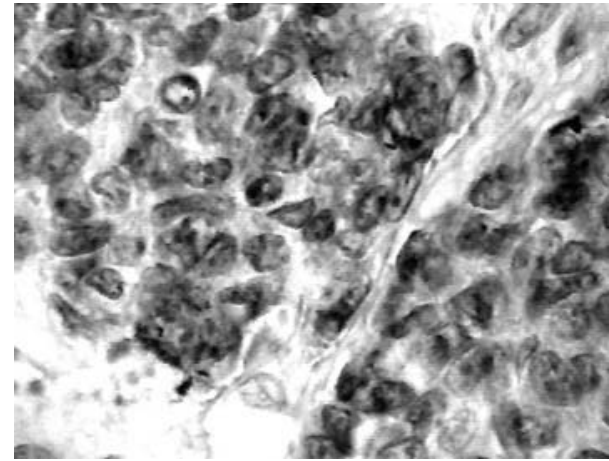

Figure 5 A few carcinoembryonic antigen positive cells in case 2 .

\section{Take home messages}

- We report two additional cases of small cell sweat gland carcinoma in childhood, confirming the original observation describing two patients of 2 and 5 years of age harbouring cutaneous tumours

- The differential diagnosis from other small blue cell tumours involving the skin is often difficult

- The prognosis of these tumours appears to be good

and cytokeratin. However, only one of the two cases in the original report and one of our two cases showed some cells with carcinoembryonic antigen positivity. Neurone specific enolase was not tested in previous cases and positivity in some cells of case l only does not add substantial data to the nosology of this tumour. Chromogranin and CD56 negativity in both cases argues against a neuroendocrine differentiation. This immunohistochemical feature, the topographical site of the tumours, and the electron microscopy of one of the original cases argue in favour of sweat gland differentiation in these tumour cells.

"The accurate diagnosis of small cell carcinoma of sweat gland in childhood requires an awareness of the dermalhypodermal position of the tumour and the negative immunohistochemical characteristics of the well known small blue cell tumours at this age"

The prognosis of small cell sweat gland carcinoma appears to be good. Although two cases (one each of the original report and our series) were recent, the other two had four and five years of follow up without recurrence or evidence of metastasis.

Small cell sweat gland carcinoma of childhood appears to be a discrete entity that should be taken into consideration when evaluating a small cell tumour involving the skin at this age.

\section{NOTE ADDED IN PROOF}

Patient 2 developed cervical lymph node metastasis one year after the initial diagnosis.

\section{Authors' affiliations}

R Drut, Department of Pathology, Children's Hospital, 1900, La Plata, Argentina

O P Giménez, Department of Anatomic Pathology, Hospital Lucio Molas, Santa Rosa, La Pampa, Argentina 
J Oliva, Department of Pathology, Children's Hospital, Mendoza, Argentina

Correspondence to: Dr R Drut, Department of Pathology, Children's Hospital, 1900, La Plata, Argentina, patologi@netverk.com.ar

Accepted for publication 25 March 2005

\section{REFERENCES}

1 Busam KJ, Gellis S, Shimamura A, et al. Small cell sweat gland carcinoma in childhood. Am J Surg Pathol 1998;22:215-20.

2 Gherardi G, Marvaggio C, Stiglich F. Parotid metastasis of Merkel cell carcinoma in a young patient with ectodermal dysplasia. Diagnosis by fine needle aspiration cytology and immunocyłochemistry. Acta Cytol 1990;34:831-6.

3 Schmid C, Beham A, Feichtinger J, et al. Recurrent and subsequently metastasizing Merkel cell carcinoma in a 7-year-old girl. Histopathology 1992;20:437-9.

4 Goldenhersh MA, Prus D, Ron M, et al. Merkel cell tumor masquerading as granulation tissue on a teenager's toe. Am J Dermatopathol 1992; 14:560-3.

5 Berg JW, McDivitt RW. Pathology of sweat gland carcinoma. Pathol Annu 1968:3:123-44.

6 Wick MR, Goellner JR, Wolfe JT 3rd, et al. Adnexal carcinomas of the skin. I. Eccrine carcinomas. Cancer 1985;56:1147-62.

7 Swanson PE, Cherwitz DL, Neumann MP, et al. Eccrine sweat gland carcinoma: an histologic and immunohistochemical study of 32 cases. J Cutan Pathol 1987; 14:65-86. 